\title{
DEVELOPMENT OF TERRESTRIAL CONCENTRATOR MODULES USING HIGH-EFFICIENCY MULTI-JUNCTION SOLAR CELLS
}

\author{
M.J. O’Neill ${ }^{1}$, A.J. McDanal ${ }^{1}$, P.A. Jaster ${ }^{2}$ \\ ${ }^{1}$ ENTECH, Inc., 1077 Chisolm Trail, Keller, TX 76248, ²3M Center, 236-1B-38, St. Paul, MN 55144
}

\begin{abstract}
For over two years, ENTECH has been developing terrestrial concentrator modules using high-efficiency multi-junction (MJ) solar cells. By utilizing MJ cells with color-mixing Fresnel lens optics produced by $3 \mathrm{M}$, module efficiency levels of approximately $30 \%$ can be realized. Such high efficiency levels provide excellent economic leverage on all area-related costs (lenses, structures, land, etc.) of concentrator systems. ENTECH's new modules build upon a successful heritage of concentrator modules and systems developed over the past two decades. This paper summarizes progress on the development of the new concentrator module, including outdoor measurements on mini-concentrator modules employing colormixing lenses and $\mathrm{MJ}$ cells. A recently tested miniconcentrator module has achieved over 30\% net operational efficiency, which is believed to be the first time the $30 \%$ barrier has been broken for any solar technology.
\end{abstract}

\section{INTRODUCTION AND BACKGROUND}

ENTECH has been involved in photovoltaic concentrator technology for terrestrial applications for many years [1-3]. Fig. 1 shows ENTECH's silicon-cell-based terrestrial concentrator module, which uses a large acrylic Fresnel lens ( $84 \mathrm{~cm}$ wide) to focus sunlight at $21 \mathrm{X}$ concentration onto air-cooled silicon photovoltaic cells $(4 \mathrm{~cm}$ wide). These large ( 3 sq.m. aperture) concentrator modules are mounted in two-axis sun-tracking arrays. A small array containing two modules is called a SunLine $\AA$, as shown in Fig. 2. A large array containing 72 modules is called a SolarRow®, as shown in Fig. 3.

The performance of these terrestrial silicon concentrators has been excellent in a number of installations. For example, Fig. 4 compares the long-term performance of several $20 \mathrm{~kW}$ photovoltaic arrays, all located side-by-side at Davis, California, and independently measured by the DOE-sponsored PVUSA project [4]. The ENTECH array at the PVUSA site is a 60module SolarRow, the performance leader of all the array types installed at PVUSA.

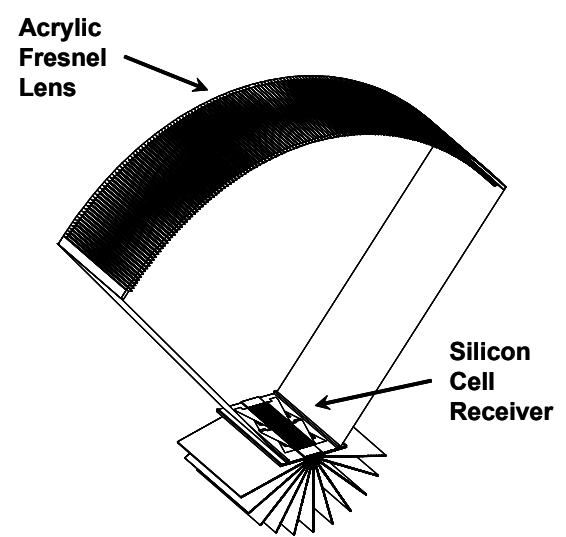

Fig. 1 - ENTECH's Silicon PV Concentrator Module

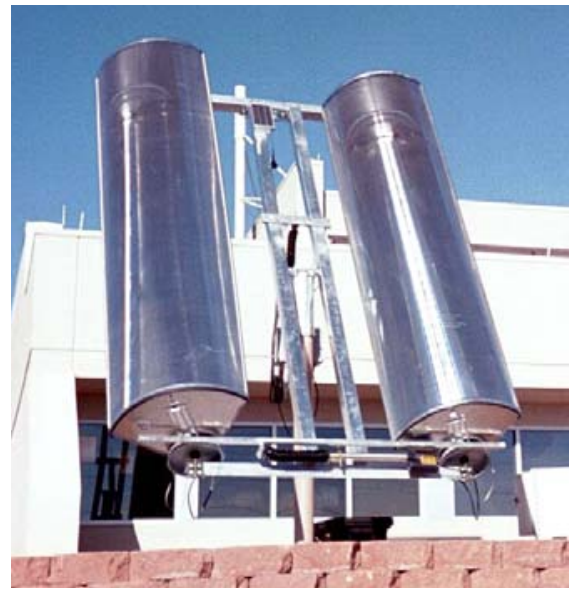

Fig. 2 - SunLine Array

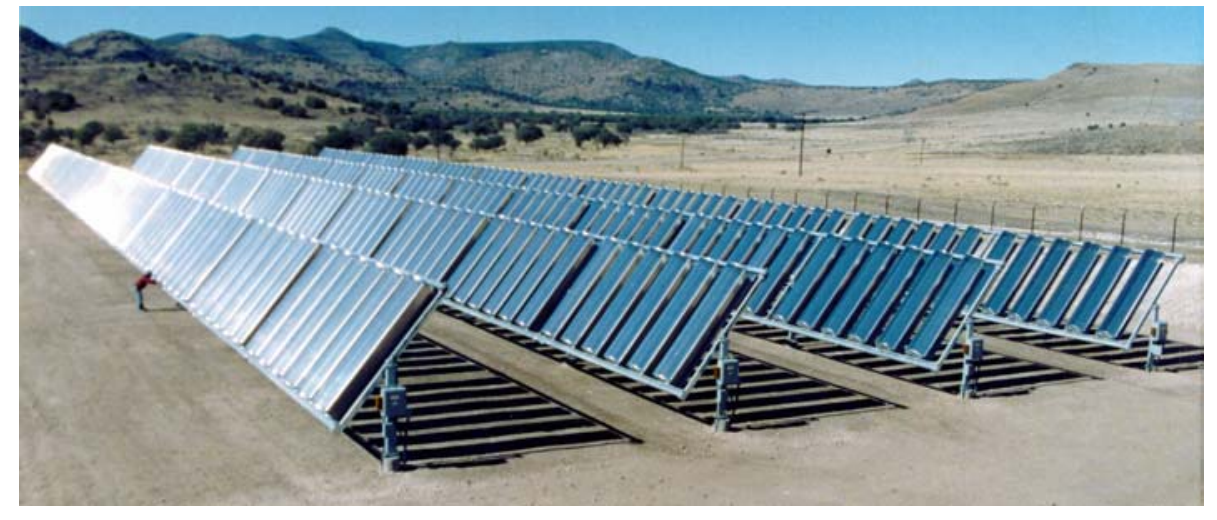

Fig. 3 - Four SolarRow Arrays 
ENTECH has also been involved in photovoltaic concentrator technology for space applications for many years [5-6]. ENTECH's current space concentrator module uses a small silicone Fresnel lens $(8.5 \mathrm{~cm}$ wide) to focus sunlight at $8.5 \mathrm{X}$ concentration onto radiation-cooled triple-junction photovoltaic cells $(1.0 \mathrm{~cm}$ wide). These space concentrators provide outstanding performance and reliability. The SCARLET® (Solar Concentrator Array using Refractive Linear Element Technology) array flawlessly powered both the spacecraft and the ion engine on the recently completed NASA/JPL Deep Space 1 mission (Fig. 5), which concluded with a spectacularly successful rendezvous with Comet Borrelly in September 2001. One key to the excellent performance of these space concentrators has been their use of patented colormixing lenses, which overcome normal lens chromatic aberration effects on multi-junction cell performance [6-7].

Over the past three years, ENTECH has developed a new space concentrator array technology, called the stretched lens array (SLA) [8-10]. This new SLA (Fig. 6) provides higher performance at dramatically reduced mass compared to the SCARLET array. As part of the development of the SLA, ENTECH routinely performs outdoor testing of stretched lenses, multi-junction cells, and combined lens/cell modules, to ensure their proper functionality before sending them to NASA for additional testing. Despite the fact that the cells used in SLA are optimized for the AMO solar spectrum, they have consistently provided exceptional performance under terrestrial sunlight. This outdoor testing of SLA hardware has served as a pathfinder for the development of terrestrial concentrator modules, leading to a world-record $27 \%$-efficient mini-concentrator module two years ago [1112]. Many improvements have been made in space multijunction concentrator cells in the last two years [13]. Using the latest space concentrator cells under the latest stretched lenses, the authors have recently measured over 30\%-efficient mini-concentrator modules, as further described in the following paragraph.

\section{STRETCHED LENS MINI-CONCENTRATOR OUTDOOR PERFORMANCE TESTING}

Fig. 7 shows a stretched lens mini-concentrator module undergoing outdoor testing at ENTECH in Keller, Texas, during October 2001. This mini-concentrator used a prism-covered Spectrolab cell mounted to a copper plate, which was passively cooled by natural convection to the ambient air. For a full week, this mini-concentrator module was tested under a variety of weather conditions with a significant range of direct normal irradiance and ambient temperature levels. In addition, two different cells were used in the module on three of these days. Many of these IV curves confirmed over $30 \%$ net lens/cell module efficiency at the normal operating cell temperature corresponding to the current irradiance level and ambient air temperature. Fig. 8 shows one of these IV curves, measured for an ambient air temperature of $25 \mathrm{C}$ and a direct normal irradiance (DNI) of $851 \mathrm{~W} /$ sq.m., very close to the PVUSA rating condition for terrestrial concentrator modules [4]. The mini-concentrator module's efficiency was measured at $30.8 \%$ for this condition.

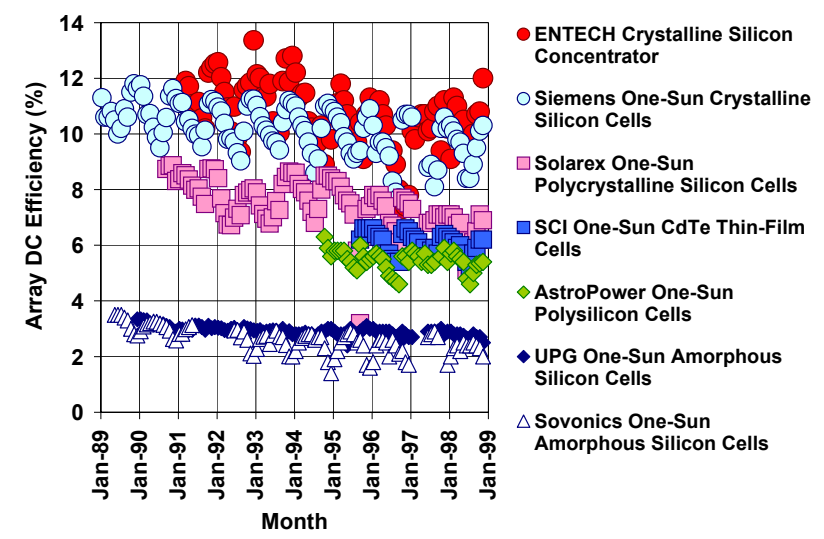

Fig. 4 - PVUSA Long-Term Performance Data

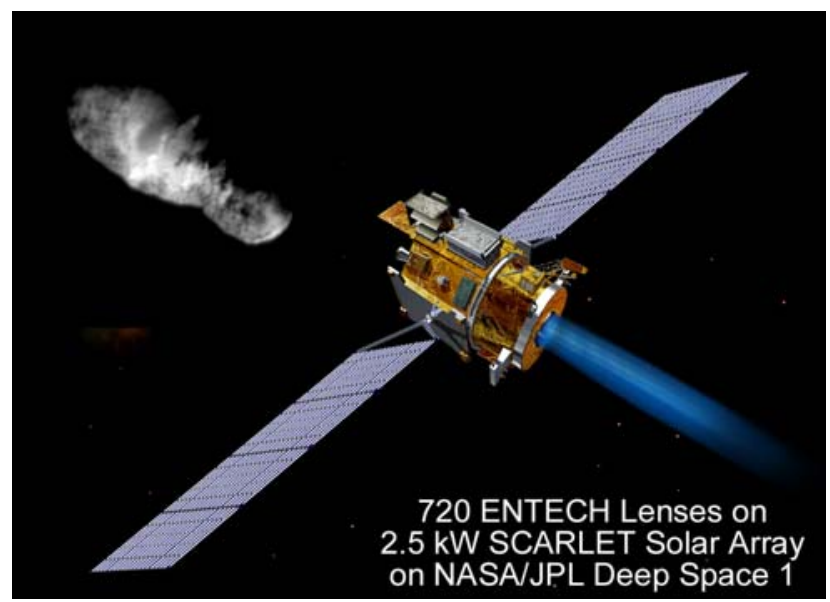

Fig. 5 - SCARLET Array on Deep Space 1

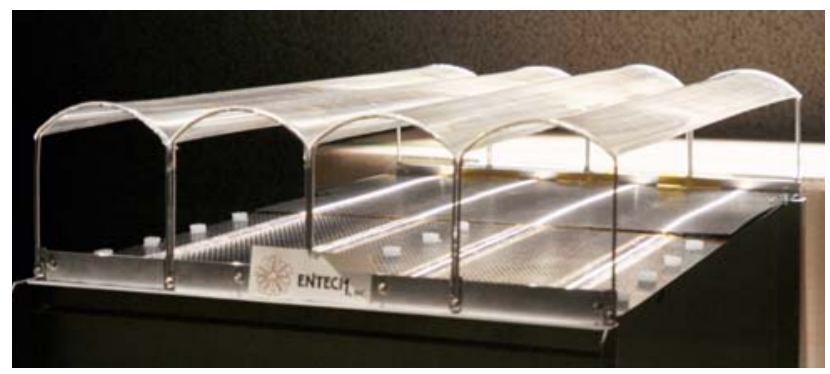

Fig. 6 - Stretched Lens Array (SLA) Prototype

Fig. 9 shows all of the mini-concentrator module efficiency data points taken during the 5 days of testing. For one cell, the average of all the module efficiency points is $29.7 \%$. For the other cell, the average of all the module efficiency points is $30.6 \%$. The composite average of all the module efficiency points for both cells is $29.9 \%$. Thirty three different IV curves taken under varying conditions confirmed over $30 \%$ net mini-concentrator module operational efficiency.

The authors believe that this is the first solar energy device to be tested outdoors under natural sunlight at over 
$30 \%$ operational solar-to-electric conversion efficiency. The highest previous efficiency which the authors have found in the literature was for a $29.4 \%$-efficient parabolic

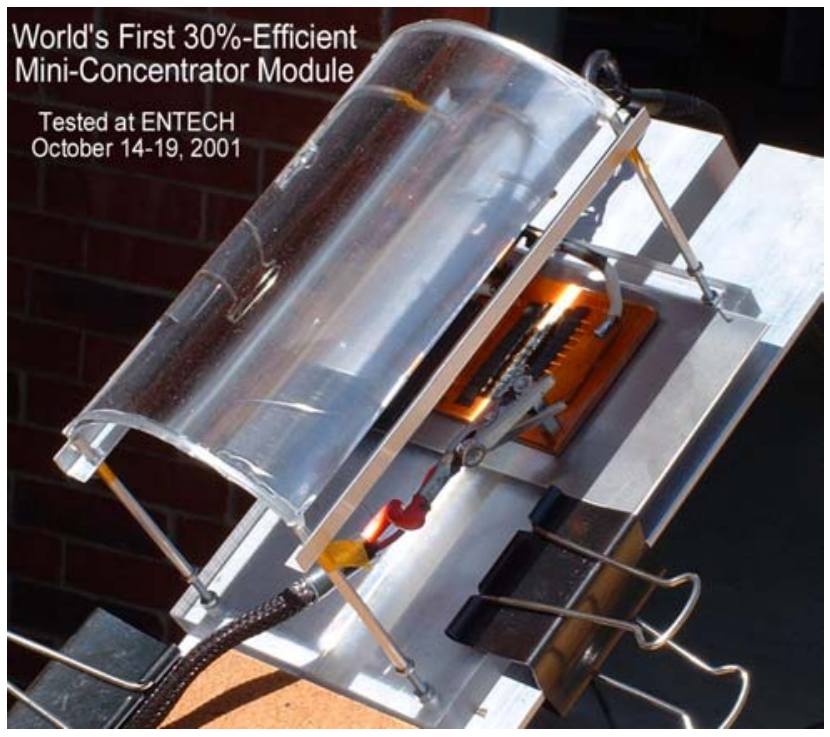

Fig. 7 - Stretched Lens Module with Spectrolab Cell

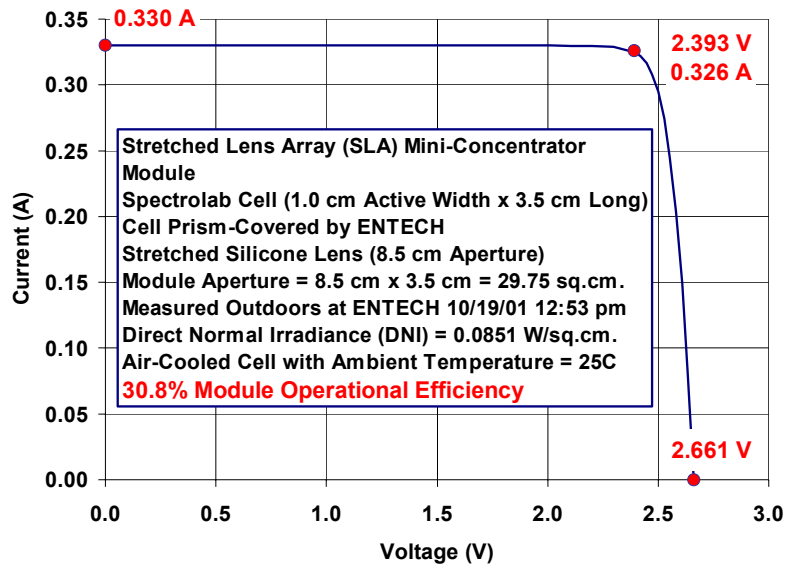

Fig. 8 - Stretched Lens Module with Spectrolab Cell

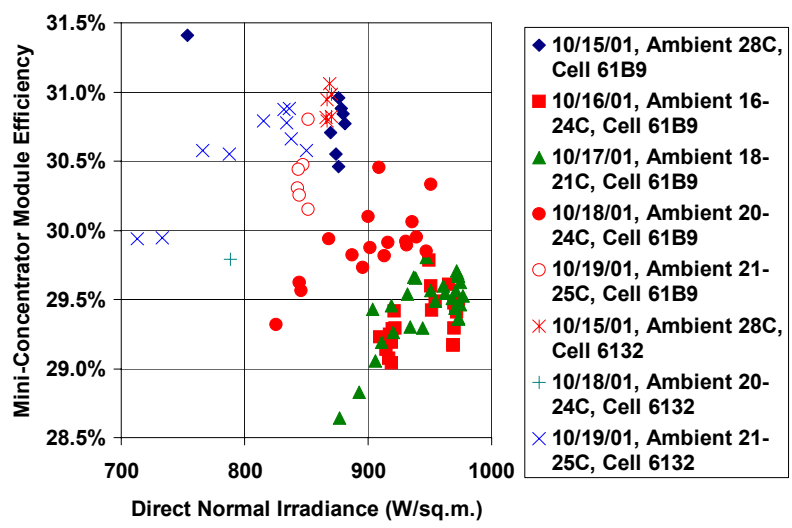

Fig. 9 - Data for 5 Days and 2 Cells dish with Stirling engine converter tested in 1984 as reported in various U.S. Department of Energy (DOE) publications, including the DOE's concentrating solar power web site (http://www.eren.doe.gov/der/csp.html). While the earlier dish/Stirling system clearly provided a more meaningful power output $(\sim 25 \mathrm{~kW})$ than the miniconcentrator modules reported here $(\sim 1 \mathrm{~W})$, the authors nonetheless believe that breaking the $30 \%$ barrier is significant, since it shows that photovoltaic concentrators can now compete head-to-head with the best solarthermal technologies on a solar-to-electric conversion efficiency basis.

Recently, EMCORE has also provided space concentrator cells to ENTECH, and several of these prism-covered cells have also been tested outdoors in a stretched lens module. Fig. 10 shows one of these modules during an outdoor test conducted in March 2002. The performance of these mini-concentrator modules with EMCORE space cells has also been excellent, as shown in Fig. 11. Indeed, ENTECH tested three different EMCORE cells in

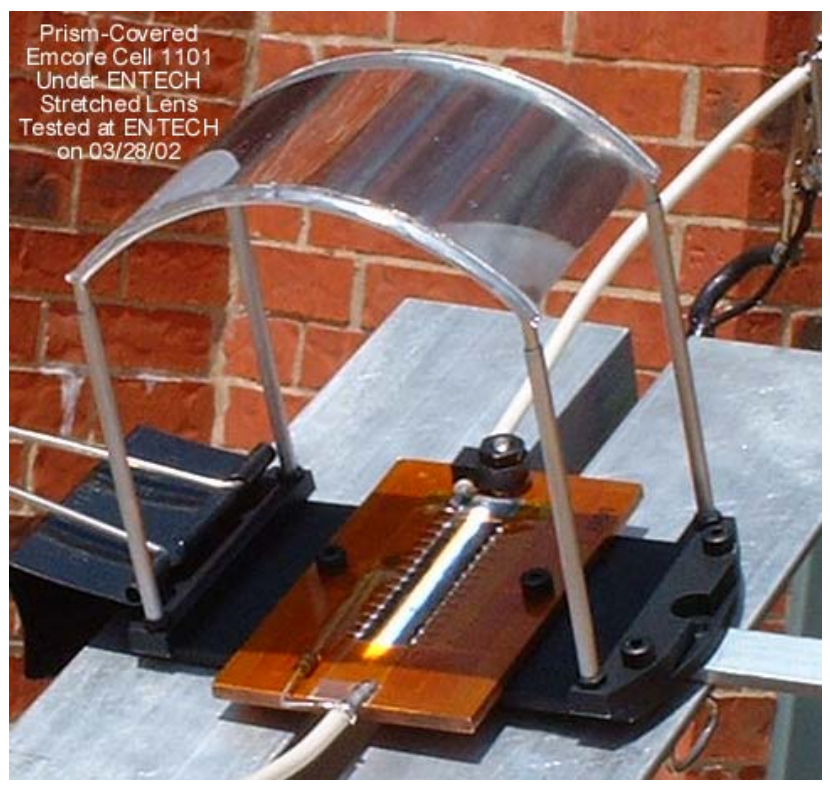

Fig. 10 - Stretched Lens Module with EMCORE Cell

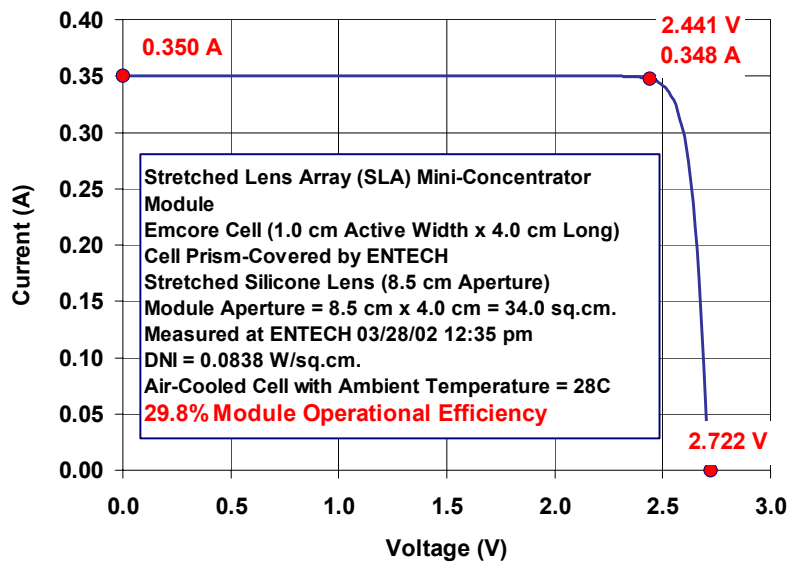

Fig. 11 - Stretched Lens Module with EMCORE Cell 
a stretched lens module, and all had operational miniconcentrator module efficiencies between $29 \%$ and $30 \%$.

Importantly, NASA recently flew ENTECH stretched lens mini-concentrator modules on the NASA Glenn Lear Jet test platform to determine their short-circuit current under space sunlight (AM0). NASA then used these Lear Jet results to calibrate their large area pulsed solar simulator (LAPSS) in measuring the full IV curves for these miniconcentrator modules. Mini-concentrators using cells from both Spectrolab and EMCORE achieved over $27 \%$ module efficiency (AM0, 25C) under the space sunlight spectrum [10]. Therefore, the same cells which have provided outstanding results under ground sunlight ( 30\% net module efficiency) have also provided outstanding results under space sunlight ( $27 \%$ net module efficiency).

\section{TERRESTRIAL CONCENTRATOR MODULE DEVELOPMENT PROGRAM}

The goal of the ongoing terrestrial concentrator module development program is to incorporate the high-efficiency MJ cells from the space concentrator program into the field-proven, large-area, mass-producible terrestrial concentrator module. By so doing, the array-level performance should approximately double compared to the present silicon-cell-based technology. This performance doubling would drastically reduce the cost per Watt of lenses, heat sinks, housings, support structures, suntracking drives, and all other area-related items, if the new module were fully compatible with the existing field-proven arrays.

Of course, at least two cost elements will increase for the new module: cells and optics. The MJ cells are approximately two orders of magnitude more expensive per sq.cm. of cell area than silicon cells. To make the cells affordable, the module optics must be modified to increase the geometric concentration ratio from $21 \mathrm{X}$ to $440 \mathrm{X}$, by focussing the sunlight in both planes rather than in a single plane. This concentration increase will be accomplished through the use of proprietary secondary optics, which clearly add to the cost of the module. Furthermore, the higher concentration level will require the MJ cells to be packaged with a heat spreader to maintain an acceptable operating cell temperature. But when both of these increased costs (packaged cells and secondary optics) are included in a system-level comparison, the $\$ / \mathrm{W}$ figure of merit is still substantially less for the new system, provided that the packaged MJ cells can be obtained or produced for a few dollars per square centimeter, and that these cells will perform reliably and efficiently over the 2-3 decade period required for terrestrial power plants.

The terrestrial concentrator development program has been more difficult that originally envisioned [11]. Extending the $\mathrm{MJ}$ cell performance envelope to the economically required higher current levels (amps per cell) and higher current density levels (amps/sq.cm.) has involved serious and unexpected challenges. But progress is being made and problems are being overcome.
The first large-area color-mixing acrylic lenses have recently been tooled and produced by $3 \mathrm{M}$ using their proprietary, high-speed, lensfilm process. Secondary optical elements have been produced in prototype form. Thermal and electrical approaches for the cell package have been developed and successfully tested at the prototype level.

\section{FUTURE PLANS}

Over the next year, the development team anticipates the completion of the development of the first full-scale (3 sq.m. aperture) terrestrial concentrator modules using MJ cells. After these modules are successfully field tested, commercialization of the new technology will begin.

\section{ACKNOWLEDGEMENT}

The authors gratefully acknowledge the technical and financial support provided by NASA, NREL, Spectrolab, EMCORE, 3M, and ENTECH, in performing the work reported here.

\section{REFERENCES}

[1] M.J. O'Neill, "Solar Concentrator and Energy Collection System," U.S. Patent No. 4,069,812, 1978.

[2] M.J. O'Neill, "Silicon Low-Concentration, Line-Focus, Terrestrial Modules," Chapter 10 in Solar Cells and Their Applications, John Wiley \& Sons, 1995.

[3] M.J. O'Neill and A.J. McDanal, "The $25 \mathrm{~kW}$ SolarRow: A Building Block for Utility-Scale Concentrator Systems," 25th IEEE PVSC, Washington, 1996.

[4] PVUSA Project Team, "1998 PVUSA Progress Report," USDOE Contract No. DE-FC04-96AL89774, 1999.

[5] M.F. Piszczor and M.J. O'Neill, "Development of a Dome Fresnel Lens/Gallium Arsenide Photovoltaic Concentrator for Space Applications," 19th IEEE-PVSC, 1987.

[6] M.J. O'Neill, "Line-Focus Optics for Multijunction Cells in Space Power Arrays," 25th IEEE PVSC, Washington, 1996.

[7] M.J. O’Neill, "Color-Mixing Lens for Solar Concentrator System and Methods of Manufacture and Operation Thereof," U.S. Patent 6,031,179, 2000.

[8] M.J. O'Neill et al., "The Stretched Lens Ultralight Concentrator Array," 28th IEEE PVSC, Anchorage, 2000.

[9] M.J. O'Neill, "Stretched Fresnel Lens Solar Concentrator for Space Power," U.S. Patent 6,075,200, 2000.

[10] M.J. O'Neill et al., "Development of the Ultra-Light Stretched Lens Array," 29th IEEE PVSC, New Orleans, 2002.

[11] M.J. O'Neill et al., "Development of Terrestrial Concentrator Modules Incorporating High-Efficiency MultiJunction Cells," 28th IEEE PVSC, Anchorage, 2000. [12] M.A. Green et al., "Solar Cell Efficiency Tables (Version 16)," Progress in Photovoltaics: Research and Applications, Volume 8, 2000.

[13] A. Stavrides et al., "Fabrication of High Efficiency III-V Multi-Junction Solar Cells for Space Concentrators," 29th IEEE PVSC, New Orleans, 2002. 